$\xi=-1$

\title{
Perception on Prolonged Standing Work in Electronic Manufacturing Company
}

\author{
Norlizaa Mohamad ${ }^{1}$, Jafri Mohd Rohani ${ }^{{ }^{*}}$, Ismail Abdul Rahman ${ }^{2}$, Anis Amira Mat Zuki ${ }^{1}$ \\ ${ }^{I}$ Faculty of Mechanical Engineering, Universiti Teknologi Malaysia, Skudai, Johor, Malaysia. \\ ${ }^{2}$ Ergonomics Excellence Centre, National Institute of Occupational Safety and Health (NIOSH),81400 Senai, Johor, Malaysia \\ *Corresponding authorE-mail:jafrimr@utm.my
}

\begin{abstract}
Prolonged standing is one of the common activities in electronic industry as the task requirement. Prolonged standing can cause discomfort on the body of the workers and can lead to injury and occupational disease. The purpose of this study is to investigate standing workers perception on the fatigue and the discomfort on their respective body region for 12 hours working time. The subjects are the 80 workers with a good health condition and at least 6 months tenure. The subject data are collected via questionnaires and Likert scale to define the discomfort, pain, and fatigue. The workers were interviewed regarding their job and perceived fatigue discomfort. The results show the domination of the lower body region with the higher mean at the lower back, legs, and foot ankle. No statistically significant differences were found between the job tenure and body part discomfort pain and fatigue. There is a significant relation between gender and discomfort pain on legs and foot ankle. The result also shows a strong relation between age and the discomfort body parts of thigh and foot ankle. The perceptions of the workers towards discomfort pain and fatigue cause by prolonged standing during performing the task. The results from this study will provide a view for industrial consultants or ergonomist with evidence to support for ergonomic interventions for prolonged standing activity such as job rotation and work-rest schedule.
\end{abstract}

Keywords: Discomfort pain; Muscle fatigue; Perception; Prolonged standing

\section{Introduction}

Industrial sector provides more opportunity in job and career development. By increasing the number of the industrial sector it is proportionally raising the number of the injuries and occupational diseases in the real life. Without most of the people realized the occupational disease and injuries directed increase the medical cost and loss of the productivity. Based on the study by the $\mathrm{Za}-$ karia et al. [1], one of the factor workplace accidents are stress and fatigue. Prolonged standing is one of the common activities in the industrial sector as the task requirement. During prolonged standing, the body weight transfers and the center of pressure movement at the feet or movement at lumbar spine where the pain develops.

Prolonged standing is defined as standing more than $50 \%$ from the total working hours during the full work shift [2]. Based on the previous literature, prolonged standing can cause health issues for the muscle fatigue and discomfort especially on the lower extremities [2][4][5]. Musculoskeletal pain and discomfort are common complaints among the workers when involved the prolonged standing task.

Perception is the organization, identification, and interpretation of sensory information in order to represent and understand the environment [6]. This can be interpret perception is understood the event or activity by using the sense or ability and also as result of perceived.

The perception of the workers can be assessed through the Borg Scale [7], questionnaire surveys [8] can be used in assessed the perception or fatigue experienced by the worker. For this study, interviews were conducted with the assembly line workers to ex- amine the subjective discomfort ratings of the body parts. It is evident from the previous research that lack of work on the perception of prolonged standing task. Moreover, there is a lack of research work has been reported in electronic industries in Malaysia where the labor force required to perform the task in 8 hours and up to 12 hours by prolonged standing. The purpose of this study was to investigate assembly line workers' perceptions of fatigue and discomfort after standing for 12 hours in electronic industry, Malaysia. The aims of this study are to investigate the perception on of the discomfort pain and fatigue at the body parts. Besides that, it is to develop the relationship between ages, gender and job tenure towards muscle fatigue and discomfort pain among the workers. This study also will provide the view of the cause for the discomfort pain and fatigue in workers perceptions. The results from this study will provide a view for industrial consultants or ergonomist with evidence to support their recommendations for the improving the workers comfort level and reducing the muscle fatigue and musculoskeletal pain while working in prolonged standing in the industry.

\section{Methodology}

The study based on the questionnaires survey by an interview the operator to measure assembly line workers' fatigue and discomfort levels. Each of the operators is interviewed individually without line leader and top management monitoring. This can reduce the variability of the result and increase the reliability of this study. Subjects were requested to provide demographic information including age, height, weight, and job tenure. As this research will investigate the relationship between age and job tenure towards 
discomfort pain and fatigue on the body parts, the demographic information are defined as below:
a) Age
i) Less than 44 (Young)
ii) More than 45 (Old)
b) Working experience
i) Less than 1 year (12 months)
ii) More than 1 year

The study group is in electronic industry that represents one of the biggest industries in Malaysia. The respondent is 80 workers performed prolonged standing task are distributed equally between male and female. The study group involved the operators at least 6 months working experience in the company. The subjects of this study were full-time employees working first shift working from $7 \mathrm{am}$ to $7 \mathrm{pm}$.

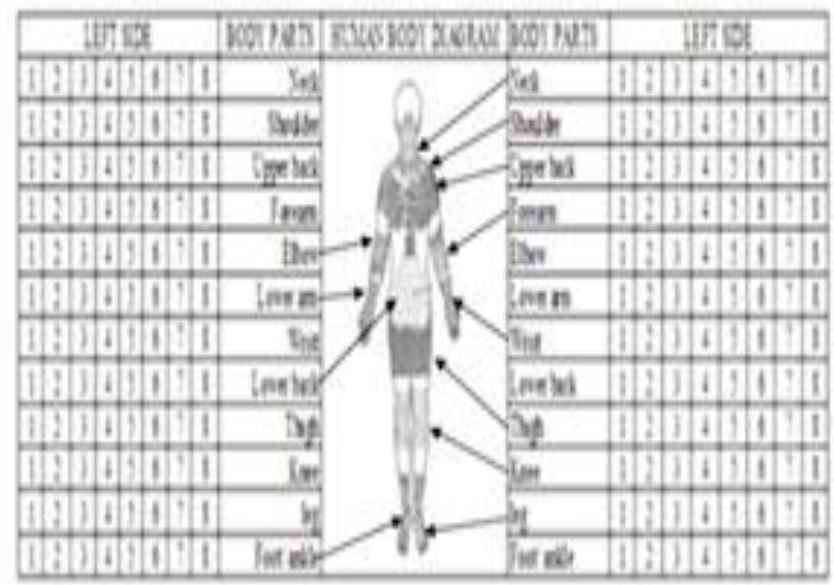

Fig. 1: Questionnaire

In the questionnaire, they were asked to rate their severity on fatigue or discomfort pain in 12 different body part (Figure 1) with Likert scale from 1 to 8 .

$$
\begin{aligned}
& 1=\text { Fatigue }, \\
& 2=\text { Numbness, } \\
& 3=\text { Tingling, } \\
& 4=\text { Swollen }, \\
& 5=\text { Strain }, \\
& 6=\text { Hot/Cold }, \\
& 7=\text { Hamstring, } \\
& 8=\text { Sprain }
\end{aligned}
$$

At the end of the interview, the workers were asked their opinion on the causes of the discomfort and pain. This questionnaire was adopted from Halim et al. [9] and some modifications have been done according to the research question and objectives. Then, the descriptive analysis are performed to describe minimum, maximum, and mean scores for the questions regarding fatigue and discomfort according to body parts for all subjects. Besides that, the opinion of the causes of the pain also will be discussed. The Spearman correlation coefficient was computed to ascertain the correlational strength between age, gender and job tenure to scores fatigue, and discomfort level in specific body regions. All analyses were performed using SPSS version 20.

\section{Results and Discussion}

\subsection{Demographic Information}

In this study, 85 workers are selected to be interviewed; however, five subjects were eliminated due to the lack of the working experience in the company (less than 6 months). The 80 workers are distributed equally between males and females.
The demographic information is summarized in Table 1. The subjects' ages ranged from 19 to 52 years old with a mean age of 30 years. The height among subjects ranged from $137.10 \mathrm{~cm}$ to $182.30 \mathrm{~cm}$ with a mean height of $159.84 \mathrm{~cm}$. Subjects' weights ranged from $35 \mathrm{~kg}$ to $86 \mathrm{~kg}$. The job tenure of subjects performed prolonged standing task position ranged from 6 months to 228 months with a mean of 59.6 months.

Table 1: Demographic information, $\mathrm{N}=80$

\begin{tabular}{lcccc}
\hline Demographic information & Minimum & Maximum & Mean \\
\hline Age & 19.00 & 52.00 & 29.86 \\
Height $(\mathrm{cm})$ & 137.10 & 182.30 & 159.84 \\
Weight $(\mathrm{kg})$ & 35.00 & 86.00 & 59.39 \\
$\begin{array}{l}\text { Working } \\
\text { (months) }\end{array}$ & experienced & 6.00 & 228.00 & 59.55 \\
Body Mass Index (BMI) & 18.6 & 25.9 & 23.2 \\
\hline
\end{tabular}

\subsection{Perception of Discomfort Pain and Fatigue on the Body Parts}

The highest mean ratings for discomfort pain are foot ankle (2.7875), lower back (2.4750) and leg (2.0250). The thigh and knee perceived least severity on discomfort pain among the workers on lower extremities. For the categories of upper extremities, shoulder (1.2750) and upper back (1.4250) shows the high rating for the discomfort. This is may be due to the task are performed by the worker by loading and unloading the workload and reaching the goods. The ratings of discomfort pain from the body part are explicated in Table 2 by mean and standard deviation.

Table 2: Result of discomfort pain and fatigue

\begin{tabular}{lcc}
\hline Body parts & Mean & Std. Deviation \\
\hline Neck & 0.5250 & 1.1904 \\
Shoulder & 1.2750 & 1.5008 \\
Upper back & 1.4250 & 1.4476 \\
Forearm & 0.6625 & 1.2319 \\
Elbow & 0.2750 & 0.9137 \\
Lower arm & 0.1000 & 0.4666 \\
Wrist & 0.3375 & 0.8993 \\
Lower back & 2.4750 & 1.8209 \\
Thigh & 0.4125 & 1.0518 \\
Knee & 0.7875 & 1.3566 \\
Leg & 2.0250 & 1.3499 \\
Foot ankle & 2.7875 & 1.6512 \\
\hline
\end{tabular}

From the result, it clearly indicates the standard deviation is higher than the means except for the lower back, leg and foot ankle. This shows the statistical dispersion of the discomfort rating is widely apart from the means. This also shows the severity of the pain for each of the workers has an enormous difference in terms of perception.

\subsection{Relationship of Age, Gender, and Job Tenure to- wards Discomfort Body}

In order to determine the correlational strength between demographic information and body part discomfort and pain, statistical analysis was computed by using Spearman correlation. The result is shown in Table 3 for analysis of correlations $(p<0.05)$ between gender, age and job tenure for the discomfort on the body parts. From the Table 4, several correlations between age and gender towards discomfort body part can be evaluated. Gender was most strongly correlated with discomfort on leg and foot ankle while standing for prolonged periods of time. In terms of age, thigh and foot ankle shows strong correlation towards discomfort body parts. There were no moderately relations between job tenure and subjective ratings of fatigue or discomfort on the body parts.

Table 3: Demographic relationship and body parts discomfort

\begin{tabular}{lllllll}
\hline Demographic & Gender & & Age & & \multicolumn{2}{c}{ Job tenure } \\
\hline $\begin{array}{l}\text { Area of } \\
\text { Fatigue }\end{array}$ & $\mathrm{r}$ & $\mathrm{p}$ & $\mathrm{r}$ & $\mathrm{p}$ & $\mathrm{r}$ & $\mathrm{p}$ \\
/Discomfort & & & & & & \\
\end{tabular}




\begin{tabular}{lllllll}
\hline pain & & & & & & \\
Neck & 0.195 & 0.082 & 0.121 & 0.286 & 0.004 & 0.972 \\
Shoulder & 0.233 & 0.038 & 0.117 & 0.301 & -0.130 & 0.249 \\
Upper back & 0.179 & 0.113 & 0.195 & 0.083 & -0.017 & 0.882 \\
Forearm & -0.037 & 0.743 & 0.041 & 0.721 & 0.011 & 0.926 \\
Elbow & -0.079 & 0.486 & -0.095 & 0.403 & 0.047 & 0.681 \\
Lower arm & -0.119 & 0.293 & -0.065 & 0.565 & 0.110 & 0.331 \\
Wrist & 0.047 & 0.679 & -0.113 & 0.317 & -0.001 & 0.992 \\
Lower back & 0.073 & 0.523 & 0.091 & 0.420 & -0.070 & 0.540 \\
Thigh & 0.005 & 0.963 & $\mathbf{0 . 2 4 8}$ & $\mathbf{0 . 0 2 6}$ & 0.025 & 0.829 \\
Knee & 0.122 & 0.282 & 0.173 & 0.125 & 0.068 & 0.549 \\
Leg & $\mathbf{0 . 4 6 0}$ & $\mathbf{0 . 0 0 0}$ & 0.109 & 0.336 & -0.028 & 0.806 \\
Foot ankle & $\mathbf{0 . 3 7 0}$ & $\mathbf{0 . 0 0 1}$ & $\mathbf{0 . 2 8 2}$ & $\mathbf{0 . 0 1 1}$ & -0.090 & 0.428 \\
\hline
\end{tabular}

Table 4 shows the mean and standard deviation of the difference gender towards discomfort leg and foot ankle. For the female, it has highest mean compared to the male. This can conclude the discomfort pain and fatigue mostly occurs in female compared to the male.

Table 4: Discomfort leg, $\mathrm{N}=80$

\begin{tabular}{llll}
\hline Gender & Mean & Std. Deviation & t \\
\hline Male & 1.4750 & 1.4320 & -3.970 \\
Female & 2.5750 & 1.0099 & \\
\hline
\end{tabular}

The result in Table 5 shows female having discomfort pain and fatigue on the foot ankle compared to male.

Table 5: Discomfort foot ankle, $\mathrm{N}=80$

\begin{tabular}{llll}
\hline Gender & Mean & Std. Deviation & t \\
\hline Male & 2.400 & 2.0102 & \multirow{2}{*}{.146 } \\
Female & 3.175 & 1.0833 & \\
\hline
\end{tabular}

Age has shown some strong correlation between thigh and foot ankle. From the Table 6 , old workers show higher mean than young workers. This proves old worker feels more discomfort pain and fatigue compared to a young worker at the thigh.

Table 6: Discomfort thigh, $\mathrm{N}=80$

\begin{tabular}{llll}
\hline Age & Mean & Std. Deviation & t \\
\hline Young & 0.3649 & 1.0413 & -1.432 \\
Old & 1.000 & 1.0955 & \\
\hline
\end{tabular}

The result also shows similar with thigh when the mean of the old worker is higher than the young worker. It can be concluded; the young worker also feels discomfort in foot ankle however not greatly as the old worker feel.

From the result, it can clearly state gender and age influence the discomfort body part and fatigue for prolonged standing activity.

Table 7: Discomfort foot ankle, $\mathrm{N}=80$

\begin{tabular}{llll}
\multicolumn{4}{c}{ Table 7: Discomfort foot ankle, $\mathrm{N}=80$} \\
\hline Age & Mean & Std. Deviation & t \\
\hline Young & 2.6892 & 1.6629 & -1.901 \\
Old & 4.000 & 0.8944 & \\
\hline
\end{tabular}

\subsection{Perception of Cause Discomfort Pain and Fatigue}

The bar chart shows the cause of the discomfort pain and fatigue among the worker based on their perception. From the chart, 55\% of the respondent consider only prolonged standing during performed the work are the cause of the pain.

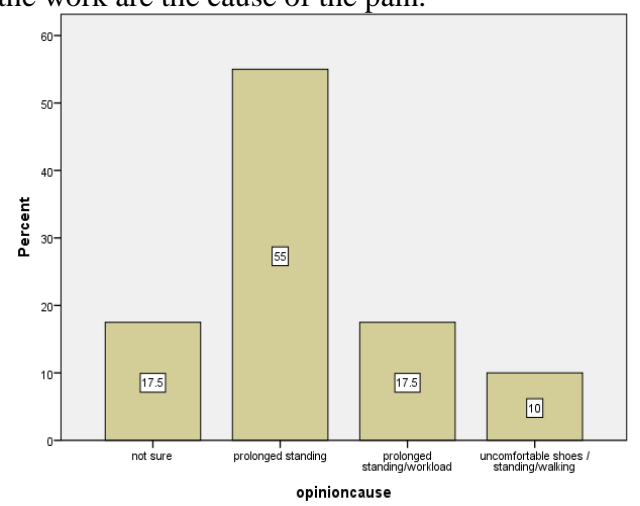

Fig. 2: Opinion based on workers perception
The percentage of the respondent for not assured the cause of the discomforting pain are same with the respondent with opinion prolonged standing together with workload as a cause with $17.5 \%$ or 14 respondent .Shoes and too much walking and standing work are one of the cause choose by the respondent for the cause of fatigue by $10 \%$ from the total respondent in this study.

Through this research by conducting questionnaire survey through an interview, it revealed that leg, lower back, and foot ankle are most discomfort pains or fatigue in the body part compared to the other parts. This result also can reach agreement when the study from an Australian reported $91 \%$ of the workers had foot complications and $49 \%$ complained precisely of painful or discomfort on feet [3]. The result of this study also relevance discomfort pain or fatigued on the body such as neck and shoulder. It was documented in the previous study the physiological discomfort experience when a worker who performs processes jobs in a long duration of standing may experience discomfort in the legs, neck and shoulder [5]. If there is no action taken for the improvement and the standing position is continuously practiced it may lead to discomfort and fatigue particularly in the lower extremities body parts such as legs and thighs, lower back, and feet [5].

In addition, it was found a report fatigue, leg muscles pain, and back ache when standing for a long period at the workplace [3]. It may common problems when performing prolonged standing task but it may lead to a severe health problems such as chronic venous disorders, circulatory problems, the possibility of increase stroke risk, difficulty in pregnancy, and degenerative damage to the joints of the spine, hip, knees and feet for the long-term consequences [5]. This study has determined the discomfort pain and fatigue on the body part when performed prolonged standing task. This will help to design specific safety intervention for the improvement.

The variable such as height, weight, age, and job tenure are associated with the discomfort rating on various body parts [10]. In this study age, gender and job tenure will be discussed with the influence of the discomfort severity level that exposed to the prolonged standing operators based on their perception.

In terms of age, there is a correlation of the body part discomfort with the young and older workers perception. Thigh $(\mathrm{r}=0.248$; $\mathrm{p}<0.05)$ and foot ankle $(\mathrm{r}=0.282 ; \mathrm{p}<0.05)$ shows the strong correlation between the different age of the workers. This proves age influences on muscle fatigue and this may result mainly from high-force exertion tasks, which are associated with different mechanisms of fatigue [11]. Besides that, shrinkage of muscles in term of size and density, causing the reduction in muscles strength when getting old [12]. However, the study by M.Garcia et al. [13] shows no correlation between age towards discomfort body parts. This can be argued through the difficulty may occur to the older operator when working in the same working posture, such as prolonged standing in comparison to younger subjects as the muscle density getting lower.

Besides that, for gender, there is a strength relation between gender and discomfort on the leg $(r=0.460 ; p<0.01)$ and foot ankle $(\mathrm{r}=0.370 ; \mathrm{p}<0.05)$. This result can be supported by the previous study reported female significantly more lower-extremity pain than their male colleagues, even more, walking compared to the males workers [14]. It was agreed by the other authors that reported female gender was strongly associated with lower extremity pain. However, there is research examined gender in relation to varicose veins and nocturnal leg cramps and found no gender effect on varicose veins when the occupation was controlled for, and effects on nocturnal leg cramps appeared limited to men [15]. The cause of the difference pain perception cannot be found but it could include hormonal, genetic or psychological factors [16].

From the perspective of the job tenure, there is no correlation with the discomfort pain and fatigue on the body. These similar with the correlations between discomfort pain on the body with the age. These result may be due to the workers already adapt with the prolonged standing environment after 6 months working. The symptoms are similar. This result can be explained through the 
research by Robert et al. [17] even not been discussed in the result the relation of job tenure with worker's complaints of foot and ankle pain, the result shows no significant differences with the worker working less than 10 years or more than 20 years. By refers to the previous study, major health risks identified were chronic venous insufficiency, the musculoskeletal pain of the lower back and feet, preterm birth, and spontaneous abortions when prolonged standing without considering the job tenure. By taking into some disagreement, [18] showed that workers with more seniority, compared to those with less seniority, experienced less discomfort in their ankles, upper legs, and upper back while wearing insoles. The result same as King, 2002[10] when the researcher was identified a strong relationship between job tenure and discomfort ratings associated with body parts when exposed to the various standing conditions. This shows the job tenure has relation with the discomfort pain and fatigue on the body part.

Furthermore, aside from investigating the experienced body regions of discomfort, this study also examine the opinion among the workers regarding the pain and fatigue. From their opinion, prolonged standing, workload, shoes and walking are the cause. It is obvious from the literature prolonged standing are the main cause however by taking into consideration shoes also become a contributor .Based on the research conducted in the past, shoes can become one of ergonomics intervention in reducing pain and discomfort in prolonged standing conditions among human operators. By selection of the correct shoes, for example, the study by King (2002) [10] shows experienced less discomfort when wearing insoles. Besides that, Prat (1990) [19], documented that viscoelastic material for shoe in-soles had been found to have the greatest long-term ability to maintain a cushioning effect since the material's shock attenuating properties performed well after 1 year of usage. Both of this study shows shoe in-soles can help in reducing the discomfort for prolonged standing and as a proved the shoe selection can cause the discomfort pain and fatigue.

It has been known for some time that prolonged standing can associate with varicose veins. A worker is suspected to have varicose vein when their leg's veins become twisted and swollen [5]. Based on Halim et al. (2011) [5], varicose vein occurs when the workers sustained high pressure while performing jobs in standing position, and normally the pain in the legs will be felt when they are standing or walking. This may cause the workers think walking is one of the causes for their discomfort pain even the main cause it prolonged standing. This can be explained through the research conducted by Tuchsen et al. (2005), which found an excess of hospitalization for varicose veins among both women and men who stood or walked at least $75 \%$ of the time at work, in a large population-based study of Danish workers interviewed by telephone; effects of walking were not distinguished from standing [20]. A study reported that 50 percent of working hours of standing exhibited a higher frequency of Chronic Venous Insufficiency (CVI) than workers who spent less time in standing.

\section{Conclusion}

In conclusion, this study found the discomfort pain and fatigue occurs mostly in lower extremities of the body parts such as leg, lower back, and foot ankle. This study found several correlations among gender and age towards discomfort pain on the body part. In addition, there is no relationship between job tenure towards body part discomfort. From the perception of the operators toward discomfort pain and fatigue, more than 50 percent of the operator realized prolonged standing are the main cause. More controlled studies are needed with a larger number of subjects to examine further the relationship between age and job tenure towards the body discomfort while standing for prolonged periods of time. In order to minimize the risk of fatigue and discomfort pain, implementation of ergonomic interventions such as modifying work rest schedule and job rotation should take into consideration.

\section{Acknowledgement}

The authors would like to acknowledge National Institute of Occupational Safety and Health (NIOSH) Malaysia, especially the Ergonomics Excellence Centre (EEC) division for providing facilities and assistance in performing this experiment.

\section{References}

[1] Zakaria, N. H., Mansor, N., \& Abdullah, Z. (2012). Workplace accident in Malaysia: most common causes and solutions. Business and Management Review, 2(5), 75-88.

[2] Tomei F, Baccolo TP, Tomao E, Palmi S, Rosati MV. (1999). Chronic venous disorders and occupation. Am J Ind Med;36:653-65.

[3] Marr SJ, Quine S. (1993). Shoe concerns and foot problems of wearers of safety footwear. Occup Med; 43:73-77

[4] Redfern, MS; Cham, R. (2000) The influence of flooring on standing comfort and fatigue. Am Ind Hyg Assoc J; 61: 700-708

[5] Halim, I., Omar, A. R., Saman, A. M., \& Othman, I. (2011). A review on health effects associated with prolonged standing in the industrial workplaces. IJRRAS, 8(1), 14-21.

[6] Schacter, D.L.; Gilbert, D.L.; Wegner, D.L. (2011). Psychology. Worth Publishers.

[7] Miedema MC, Douwes M, Dul J. (1997). Recommended maximum holding times for prevention of discomfort of static standing postures. Int J Ind Ergon;19:9-18.

[8] Van Dieën JH, Oude Vrielink HH. (1998). Evaluation of work-rest schedules with respect to the effects of postural workload in standing work. Ergonomics;41:1832-44.

[9] Halim, I., Omar, A. R., Saman, A. M., Othman, I., \& Ali, M. A (2010). Development of a questionnaire for prolonged standing jobs at manufacturing industry. Advances in human factors, ergonomics, and safety in manufacturing and service industries, 253-261.

[10] King, P., M. (2002). A comparison of the effects of floor mats and shoe in-soles on standing fatigue, Applied Ergonomic 33. 477-484

[11] Wojcik, L. A., Nussbaum, M. A., Lin, D. D., Shibata, P. A., \& Madigan, M. L. (2011). Age and gender moderate the effects of localized muscle fatigue on lower extremity joint torques used during quiet stance. Human Movement Science, 30, 574-583.

[12] Noor, M., Azizzati, S. N., Ahmad, I. N., Wahab, N. A., \& Ma'arof, M. I. N. (2013). A Review of Studies Concerning Prolonged Standing Working Posture. In Advanced Engineering Forum (Vol. 10, pp. 131-136). Trans Tech Publications.

[13] Garcia, M. G., Läubli, T., \& Martin, B. J. (2015). Long-term muscle fatigue after standing work. Human Factors: The Journal of the Human Factors and Ergonomics Society, 0018720815590293.

[14] Laperri 'ere, E.: (2014) “ Le travail de serveuse de restaurant.” PhD diss.,Department of Biological Sciences, University of Qu'ebec at Montr'eal,Montr'eal, QC.

[15] Bahk, J. W., Kim, H. Jung-Choi, K. (2012). Relationship betweenprolonged standing and symptoms of varicose veins and nocturnal leg cramps among women and men. Ergonomics 55:133-139.

[16] Ruau, D.; Liu, L. Y.; Clark, J. D.; Angst, M. S. \& Butte, A. J. (2012). Sex differences in reported pain across 11,000 patients captured in electronic medical records. The Journal of Pain, 13(3), 228-234.

[17] Werner, R. A., Gell, N., Hartigan, A., Wiggermann, N., \& Keyserling, W. M. (2010). Risk factors for foot and ankle disorders among assembly plant workers. American journal of industrial medicine, 53(12), 1233-1239.

[18] Orlando, A. R., \& King, P. M. (2004). Relationship of demographic variables on perception of fatigue and discomfort following prolonged standing under various flooring conditions. Journal of occupational rehabilitation, 14(1), 63-76.

[19] Prat, D. J. (1990). Long term comparison of some shock attenuating insoles, Prosthetics and Orthotics International 14. 59-62.

[20] Tüchsen, F., Hannerz, H., Burr, H., \& Krause, N. (2005). Prolonged standing at work and hospitalisation due to varicose veins: a 12 year prospective study of the Danish population. Occupational and Environmental medicine,62(12), 847-850.

[21] Graf, M., Krieger, R., Läubli, T., \& Martin, B. J. (2015).. Should we recommend people to stand more than sit at work? Paper presented at the 19th Triennial Congress of the International Ergonomics Association, Melbourne, Australia. August. 